\title{
Neue Studie zur Innovationsfähigkeit der deutschen Industrie
}

Industrieunternehmen gelten als überdurchschnittlich innovativ. Doch befragt nach ihrem eigenen Unternehmen sieht die Führungsriege der hiesigen Industrie noch Handlungsbedarf. Dies zeigt jedenfalls eine aktuelle Studie. Sie wurde vom Marktforschungsinstitut Forsa im Auftrag des Spezialchemiekonzerns Altana durchgeführt.

$\mathrm{D}$ en Unternehmen mangelt es an Innovationskultur. Das macht auch jungen Industrie-Talenten $\mathrm{zu}$ schaffen: Sie arbeiten häufig nicht in einem Umfeld, in dem sie ihr Innovationspotenzial voll entfalten können. Dies sind Ergebnisse des neuen „Industrie-Innnovationsindex“, für den branchenübergreifend 250 Topentscheider sowie 250 Berufseinsteiger in deutschen Industrieunternehmen befragt wurden.

Die Innovationsfähigkeit eines Industrieunternehmens hat einen starken Einfluss auf den wirtschaftlichen Erfolg - davon sind 90 Prozent der deutschen Industriemanager überzeugt. Befragt nach dem eigenen Unternehmen, ergreifen die Manager jedoch Zweifel. Insgesamt schätzt der Industriesektor seine Innovationsfähigkeit zwar als gut ein. In der Studie ergibt sich ein Innnovationsindex-Wert von 142 - ein Wert über 100 ist positiv. Aber nur zwei von fünf Managern sehen ihr Unternehmen im oberen Drittel einer Bewertungsska- la von 1 bis 10. Und nur vier Prozent geben ihrer Firma die Bestnote. „Die Ergebnisse überraschen - beim Thema Innovationsfähigkeit hat die deutsche Industrie ganz klar noch Luft nach oben. Gerade in Deutschland müssen wir uns die Frage stellen, wie die Möglichkeiten hier besser ausgeschöpft werden können“, sagt Dr. Matthias L. Wolfgruber, Vorstandsvorsitzender der Altana Gruppe.

\section{Innovationsförderndes Arbeitsumfeld}

Für Unternehmen ist es sehr wichtig, dass eine Kultur herrscht, in der Innovationen reifen können. Wichtig für ein innovationsförderndes Arbeitsumfeld ist zum Beispiel, dass Vorgesetzte wertschätzend auf ungewöhnliche Vorschläge reagieren. Denn gerade neue Pfade und Blicke über den Tellerrand tragen zur Entwicklung von Innovationen bei. Doch zeigt die Studie, dass in zwei Dritteln der Unternehmen Ideen abseits der Norm nicht immer positiv aufgenommen werden. Eine aktive Förderung von unkonventionellen Denkund Vorgehensweisen findet nach Angaben der Berufseinsteiger sogar nur in 15 Prozent der Unternehmen statt. Das bestätigen auch die Manager: Hier sehen nur zwölf Prozent im eigenen Unternehmen eine breite Akzeptanz für Mitarbeiter, die Neuland wagen wollen. Selbst vermeintliche Standards zur Innovationsförderung wie ein betriebliches Vorschlagswesen sind in weniger als einem Viertel der Unternehmen voll etabliert.

Wie die Studie zeigt, sind die Manager sich durchaus im Klaren darüber, dass sie nicht mit bestem Beispiel vorangehen: Nur 17 Prozent leisten nach eigenen Angaben persönlich einen optimalen Beitrag, um Innovationen zu fördern. Dabei wissen die Entscheider um die positiven Auswirkungen einer starken Innovationsfähigkeit. So halten 41 Prozent einen sehr hohen Innovationsgrad für notwendig, um sich vom Wettbewerb abzuheben.

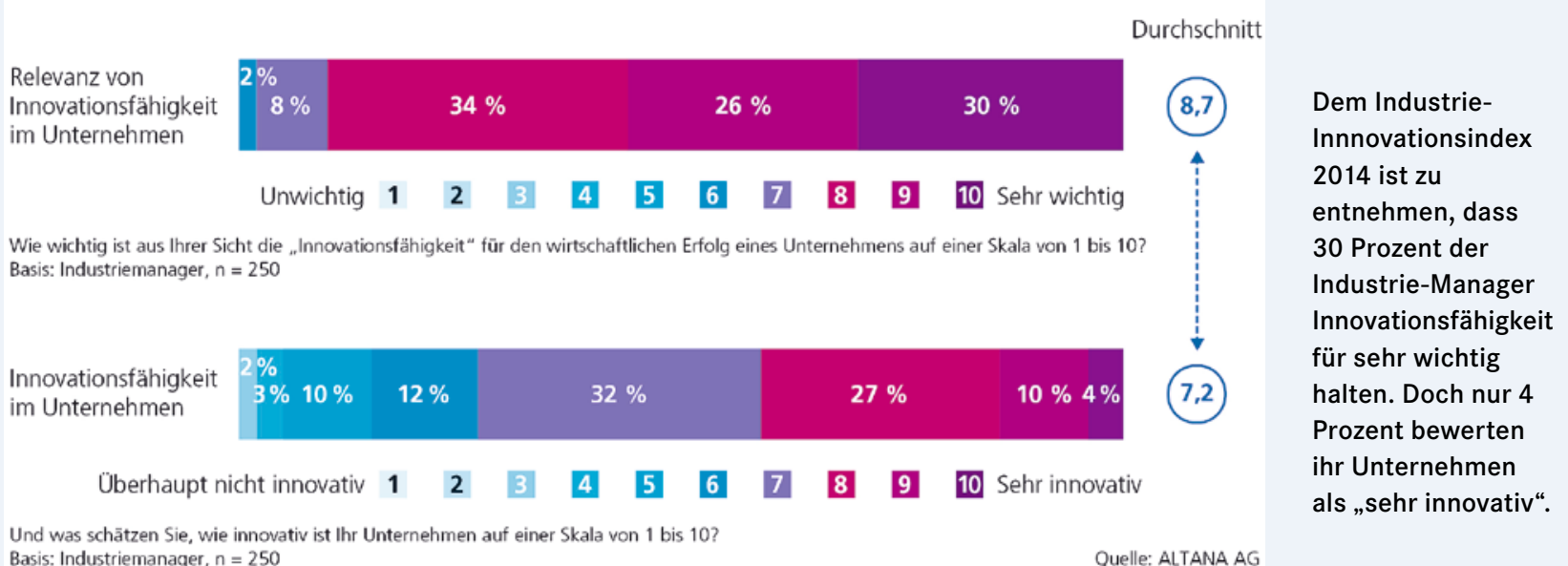

